\title{
Simulasi Swarm Robot Dengan Pendekatan Rayap Pada Masalah Clustering
}

\author{
Ketut Bayu Yogha Bintoro* ${ }^{1}$, Widodo Prijodiprodjo ${ }^{2}$ \\ ${ }^{1}$ FMIPA Jurusan Ilmu Komputer Universitas Udayana, Bali \\ ${ }^{2}$ FMIPA Universitas Gadjah Mada, Yogyakarta \\ E-mail : ${ }^{* 1}$ ketut.bayu@cs.unud.ac.id, ${ }^{2}$ widodo@ugm.ac.id
}

\begin{abstract}
Abstrak
Pendekatan rayap yang merupakan salah satu metode dalam rumpun swarm intelligence yang dapat mengatasi masalah clustering, pada penelitian ini pendekatan rayap dilihat dari sudut pandang pemodelan berbasis agent dan diimplementasikan ke dalam swarm robot. Penelitian ini penting untuk mengembangkan model pendekatan rayap pada kasus kasus nyata terutama pada masalah clustering, untuk mengimplemantasikan model yang diperoleh dari studi literatur maka dibuatkan simulasi untuk menggambarkan secara detail proses yang terjadi dalam menangani masalah clustering.

Pendekatan IODA digunakan untuk memodelkan interaksi yang terjadi didalam simulasi, pendekatan ini di sesuaikan dengan perangkat pengembangan yang digunakan yaitu NETLOGO. Penggunaan IODA menjadi suatu kontribusi untuk mengembangkan metodologi ini, terutama pada NETLOGO disamping pengimplementasian komunikasi tidak langsung dan optimasi pencarian yang dapat membentuk clister lebih cepat dari penelitian sebelumnya.
\end{abstract}

Kata kunci-Pendekatan rayap, simulasi, IODA, clustering, agent

\begin{abstract}
Termites approach is one of the method in swarm intelligent field which used to handle clustering problem. In this research, termites approach are in agent metodology point of view and implemented to swarm robot. This research is important to developing termites model in some real cases especially in clustering problem, to implement this model gathered from literatur study, we used simulation to give detail model about clustering solving process.

IODA metodologi is used to modelling the interaction in simulation, this approach is appropriate with NETLOGO as development tool. The involve of IODA has become one of the contribution to develop this in NETLOGO beside the implementation of indirect commun ication and searching optimization that can makes clustering process faster than the previous research.
\end{abstract}

Keywords-Termites approach, Simulation, IODA, clustering, agent.

\section{PENDAHULUAN}

$\mathrm{T}$ opik utama pada penelitian ini adalah membuat simulasi robot berkelompok atau swarm robot yang memiliki perilaku seperti rayap untuk menyelesaikan masalah clustering. Pendekatan rayap adalah salah satu pendekatan pada rumpun ilmu kecerdasan kelompok dimana salah satu model perilakunya dapat dijadikan model untuk menyelesaikan masalah clustering. Model perilaku tersebut kemudian diimplementasikan pada swarm robot..

Umumnya swarm robot menirukan salah satu model dalam kecerdasan buatan seperti semut, rayap, dan lain sebagainya [1]. Pendekatan rayap digunakan sebagai pendekatan untuk menyelesaikan masalah clustering karena konsep dasar pendekatannya sesuai untuk 
menyelesaikan masalah clustering dan jika dibandingkan dengan pendekatan semut, pendekatan rayap masih jarang digunakan pada masalah clustering sehingga penting untuk dapat menciptakan atau mengembangkan pendekatan rayap untuk menyelesaikan masalah clustering agar ada banyak alternatif atau sebagai pembanding yang dapat dipakai untuk menyelesaikan masalah clustering.

Masalah clustering banyak diaplikasikan pada berbagai macam bidang sehingga jika dilihat dari sisi edukasi dan penelitian, bagaimana proses pembentukan clustering dari tahap inisialisasi hingga tahap pembentukan clustering menjadi penting untuk diketahui, untuk menggambarkan proses clustering tersebut dibuatlah program simulasi, selain itu dengan menggunakan program simulasi yang diimplementasikan dalam bentuk swarm robot dapat lebih mudah mem-visualisasikan model pendekatan rayap yang digunakan dan langkah - langkah dari pendekatan rayap untuk masalah clustering sehingga memudahkan pengguna sistem dalam mempelajari konsep clustering terutama yang menggunakan pendekatan rayap sebagai model perilakunya.

Penelitian sebelumnya seperti $[2,3,4]$ masih berfokus pada pembuatan perilaku individu robot rayap tanpa melihat pendekatan rayap secara utuh yaitu tanpa menggunakan stigmergy kualitatif dan model interaksi yang terjadi diantara anggota koloni rayap.

\section{METODE PENELITIAN}

\section{Desain Sistem}

Tahapan ini menentukan parameter-parameter yang akan digunakan pada proses simulasi. Parameter-parameter tersebut antara lain :

- Jumlah robot (Penanda dan Pekerja)

Parameter pengaturan jumlah robot yang digunakan pada proses pencarian solusi.

- Jumlah cluster (Berdasarkan Warna)

Jumlah cluster yang terbentuk sesuai dengan jumlah warna yang dipakai pada proses simulasi.

- Intensitas Objek (density)

Jumlah objek yang diinisialisasi.

- Kecepatan gerak (speed)

Menentukan kecepatan gerak robot rayap

- De rajat pencarian

Sudut pencarian robot rayap dalam menemukan solusi baik rayap penanda maupun pekerja.

Mekanisme pembagian tugas pada rayap mengakibatkan adanya dua jenis robot rayap yang digunakan [5], yaitu robot rayap marker dan robot rayap pekerja. Goal pada raya marker / penanda adalah menandai semua objek yang ada pada lingkungan, sedangkan goal pada rayap pekerja adalah membentuk cluster sesuai karakteristiknya.

Menentukan aturan-aturan jalannya simulasi, aturan-aturan ini terkait dengan perilaku kelompok dan jalannya simulasi. Aturan-aturan untuk rayap pekerja lain :

- Robot rayap pekerja bertugas untuk membuat cluster objek sesuai dengan karakteristiknya masing-masing, robot rayap pekerja secara random memilih jenis objek tertentu dan seterusnya konsisten mengambi objek yang pertama kali dipilih.

- Berkomunikasi secara tidak langsung dengan robot rayap marker menggunakan feromon (kualitatif stigmergy).

- Agent hanya dapat mengangkut satu objek pada setiap kali proses dan langsung meletakkannya pada kelompok data yang tepat serta tidak dapat mengganti objek tersebut dengan objek lainnya [6].

IJCCS Vol. 6, No. 1, Jan 2012: 33-42 
- Robot rayap bekerja secara reaktif sesuai dengan tujuan yang diberikan. Robot rayap bergerak bersamaan dan koordinasi DESENTRALISASI.

- Setiap robot rayap pekerja bergerak secara acak dan hanya mengambil objek yang telah ditandai oleh robot rayap marker

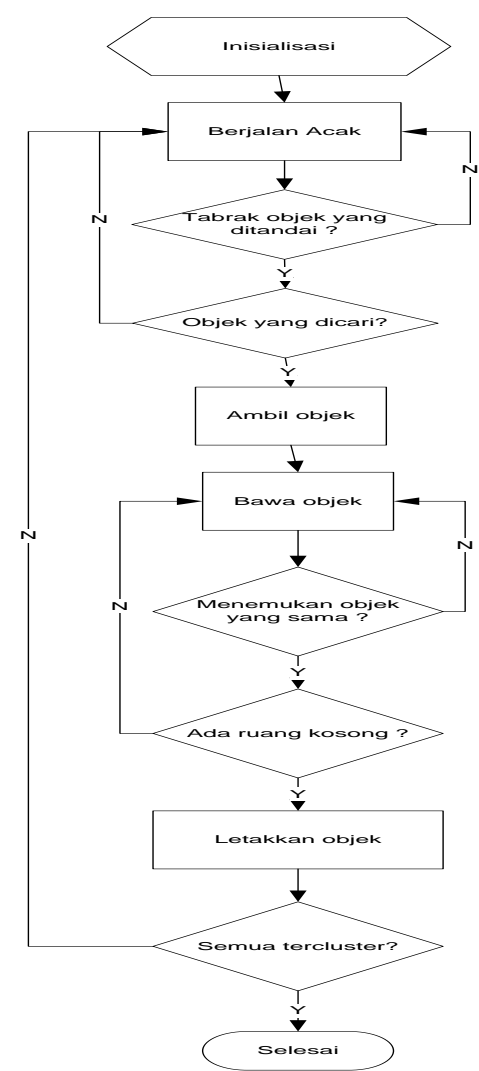

Gambar 1. Perilaku rayap pekerja

Gambar 1 memperlihatkan diagram alir robot rayap pekerja. Robot rayap pekerja hanya mengambil objek yang telah sebelumnya ditandai oleh robot rapat penanda. Objek tersebut sebelumya telah memiliki karakteristiknya masing-masing. Robot marker hanya menandai objek tersebut untuk mengaktivasi karakteristik objektersebut agar menarik robot pekerja mengambil objek tersebut. Robot pekerja secara spesifik memilih salah satu warna yang dicari pada simulasi, robot tersebut tidak mengenali kesemua warna yang ada pada simulasi.

Gambar 2 menjelaskan tentang Aturan-aturan pada robot rayap marker antara lain :

- Rayap pekerja bergerak acak untuk menemukan objek.

- Jika menemukan objek,rayap marker akan meninggalkan feromon pada objek tersebut dengan tujuan menstimulus rayap pekerja untuk mengambil objek tersebut.

- Robot rayap marker akan terus bergerak secara bersamaan dengan rayap pekerja tetapi jika sudah tidak ada lagi objek yang ditandai, rayap ini menjadi rayap pasif didalam sistem. 


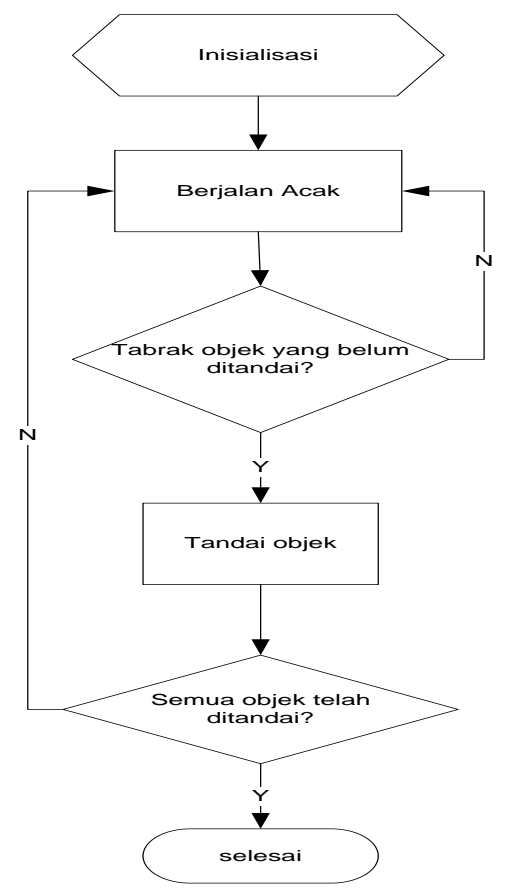

Gambar 2. Perilaku rayap penanda.

Tabel 1menjelaskan skenario penandaan objek yang dilakukan oleh robot marker pada tabel tersebut Event berarti aksi apa yang terjadi pada skenario yang menimbulkan perubahan pada lingkungan. Keadaan akhir adalah keadaan setelah terjadi event.

Tabel 1. Skenario penandaan objek

\begin{tabular}{|l|l|}
\hline Skenario : Menandai Objek \\
\hline Element yang terlibat & $\begin{array}{l}\text { Robot rayap penanda/ } \\
\text { marker, objek }\end{array}$ \\
\hline Keadaan awal & $\begin{array}{l}\text { Kedua element berada } \\
\text { pada satu lingkungan yang } \\
\text { sama dan dalam keadaan } \\
\text { acak }\end{array}$ \\
\hline Event & $\begin{array}{l}\text { Jika robot marker } \\
\text { menemukan objek maka } \\
\text { akan ditandai dengan } \\
\text { warna feromon tertentu }\end{array}$ \\
\hline Keadaan akhir & $\begin{array}{l}\text { Semua objek ditandai } \\
\text { dengan feromon }\end{array}$ \\
\hline
\end{tabular}

Tabel 2 menjelaskan tentang skenario mengambil dan membawa objek yang melibatkan robot pekerja dan objek, robot pekerja terpicu untuk mengambil objek yang telah ditandai jika objek itu memang objek dikenali, keadaan akhirnya adalah robot penanda akan membawa objek yang dia kenal kemudian mulai berjalan untuk mencari tempat meletakkan objek tersebut ditempat yang sesuai.

Tabel 2. Mengambil dan membawa objek

\begin{tabular}{|l|l|}
\hline \multicolumn{2}{|l|}{ Skenario : Mengambil dan membawa objek } \\
\hline Element yang terlibat & Robot rayap pekerja, objek \\
\hline Keadaan awal & $\begin{array}{l}\text { Kedua element berada } \\
\text { pada satu lingkungan yang } \\
\text { sama dan dalam keadaan } \\
\text { acak }\end{array}$ \\
\hline Event & Jika robot pekerja \\
\hline
\end{tabular}

IJCCS Vol. 6, No. 1, Jan 2012 : 33-42 


\begin{tabular}{|l|l|}
\hline & $\begin{array}{l}\text { menemukan objek yang } \\
\text { telah ditandai dan sesuai } \\
\text { dengan jenis feromon yang } \\
\text { dicari. }\end{array}$ \\
\hline Keadaan akhir & $\begin{array}{l}\text { Robot rayap pekerja } \\
\text { membawa objek. }\end{array}$ \\
\hline
\end{tabular}

Tabel 3 menjelaskan tentang skenario peletakkan objek dimana elemen yang terlibat antara lain robot pekerja dan objek, keadaan awalnya adalah robot pekerja membawa objek yang telah ditandai kemudian bergerak pada lingkungan pencarian, jika robot pekerja menemukan sekumpulan objek dengan warna yang sesuai dengan objek yang dibawa dan ada tempat kosong disekitar kumpulan objek tersebut maka objek akan diletakkan kemudian kembali mencari objek lainnya dengan warna yang sama dengan objek yang baru saja diletakkan.

Tabel 3. Meletakkan Objek

\begin{tabular}{|l|l|}
\hline Skenario : Meletakkan objek \\
\hline $\begin{array}{l}\text { Element yang } \\
\text { terlibat }\end{array}$ & \multicolumn{1}{|c|}{ Robot rayap pekerja, objek } \\
\hline Keadaan awal & $\begin{array}{l}\text { Robot rayap pekerja } \\
\text { membawa objek dengan } \\
\text { warna tertentu }\end{array}$ \\
\hline Event & $\begin{array}{l}\text { Jika robot pekerja } \\
\text { menemukan sekumpulan } \\
\text { objek dengan warna yang } \\
\text { sesuai dengan objek yang } \\
\text { dibawa dan ada rempat } \\
\text { kosong disekitar kumpulan } \\
\text { objek tersebut maka objek } \\
\text { akan diletakkan }\end{array}$ \\
\hline Keadaan akhir & $\begin{array}{l}\text { Robot rayap pekerja } \\
\text { meletakkan objek sesuai } \\
\text { karakteristiknya. }\end{array}$ \\
\hline
\end{tabular}

Metodologi Interaction Oriented for Designing Agent Simulation (IODA) digunakan sebagai metodologi untuk memodelkan interaksi yang terjadi diantara robot agent. Pendekatan agent dipakai karena individu robot rayap merupakan agent sehingga perancangannya harus disesuaikan [7]. Terdapat beberapa fase yang harus dilakukan dalam metodologi ini antara lain :

- Inisialisasi lingkungan

Inisialisasi lingkungan berisi interaksi apa sajakah yang terdapat pada masing-masing kelompok agent yang dapat mempengaruhi perubahan lingkungan.

- Identifikasi Agent familiy

Tahap identifikasi agent family menyatakan tahap ini menentukan kelompok agent yang terlibat pada simulasi.

- interaksi diantara robot

Tahap interaksi diantara robot, menjelaskan interaksi yang terjadi diantara robot dan objek, langkah ini dapat dikatakan merupakan inti dari permodelan interaksi yang terjadi.

- Deskripsi Persepsi dan Aksi pada setiap interaksi

Deskripsi Persepsi dan Aksi pada setiap interaksi, tahap ini mendeskripsikan setiap Interaksi yang terjadi mulai dari kondisi yang menyebabkan terjadinya interaksi hingga aksi yang menjadi respon terhadap kondisi yang ada. 
- Refined Interaction Matrix

Refined Interaction Matrix, Tahap ini, setiap interaksi yang terjadi diberikan suatu properties sebagai atribut tambahan untuk lebih memperjelas keterkaitan antara robotrobot dan objek didalam simulasi.

Penelitian ini menggunakan beberapa atribut-atribut antara lain distance dan cardinality.

Cardinality : Tingkat keterhubungan antar agent pada suatu interaksi.

distance $(d)$ adalah Jarak yang dipersyaratkan agar terjadi interaksi. ukuran yang dipakai adalah patches

Diharapkan dengan menggunakan IODA dapat memberikan kontribusi bagi pengembangan IODA pada perangkat lunak NETLOGO.

\section{HASIL DAN PEMBAHASAN}

Hal yang diuji pada tiga pengujian tersebut antara lain :

1. Menguji pengaruh ukuran lingkungan dan pergerakan robot dalam proses pembentukan cluster.

2. Menguji pengaruh jumlah robot dan derajat pencarian terhadap kecepatan pembentukan cluster pada ukuran lingkungan tertentu.

3. Menguji apakah dengan penambahan komunikasi dan derajat pencarian dapat menghilangkan stagnansi yang terjadi diakhir simulasi.

Masing-masing pengujian dilakukan sebanyak lima kali pada ukuran lingkungan yang berbeda menggunakan parameter pengujia yang berbeda- beda dan hasilnya ditampilkan dalam bentuk grafik, tabel dan plot. Berikut ini hasil pengujian dan pembahasan singkat dari ketiga pengujian yang dilakukan.

Pengujian I

Penggunaan lingkungan yang lebih besar (40 x 40) ternyata memperlambat kecepatan pembentukan cluster jika dibandingkan dengan ukuran yang lebih kecil (30 x 30). Penggunaan lingkungan dengan ukuran 40 x 40 pada lima kali percobaan yang dilakukan menghasilkan 3472 ticks yang paling minimum dan 4643 ticks yang paling maksimum. Seperti diperlihatkan

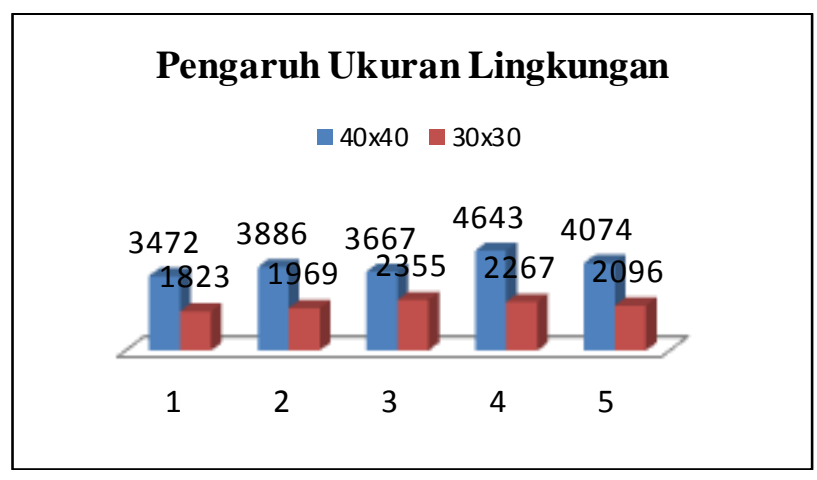

Gambar 4. Pengaruh lingkungan terhadap pembentukan cluster

Pengujian berikutnya menguji pengaruh jumlah dan sudut pergerakan robot terhadap kecepatan pembentukan cluster. Tabel 4 dan Gambar 4 memperlihatkan hasil yang diperoleh dari lima kali perngujian pada kondisi lingkungan yang berbeda. Hasil yang diperoleh

IJCCS Vol. 6, No. 1, Jan 2012: 33-42 
menampilkan bahwa penggunaan ukuran simulasi yang lebih besar memperlambar proses pembentukan cluster.

Tabel 4. Percobaan I pada lingkungan 40x40

\begin{tabular}{|c|c|c|}
\hline \multirow{2}{*}{ Percobaan } & \multicolumn{2}{|c|}{ Lingkungan } \\
\cline { 2 - 3 } & $40 \times 40$ & $30 \times 30$ \\
\hline 1 & 3472 & 1823 \\
\hline 2 & 3886 & 1969 \\
\hline 3 & 3667 & 2355 \\
\hline 4 & 4643 & 2267 \\
\hline 5 & 4074 & 2096 \\
\hline Rata-rata & 3948.4 ticks & 2102 ticks \\
\hline
\end{tabular}

Tabel 5 memperlihatkan perubahan parameter kecepatan (speed) dan derajat pencarian (degree) pada kasus yang sama, didapatkan bahwa dengan menggunakan derajat pencarian yang lebih besar tidak secara signifikan mempercepat proses pembentukan cluster hal tersebut dikarenakan letak dari objek yang sulit ditemukan pada ruang pencarian tetapi masih lebih baik daripada menggunakan derajat pencarian (0).

Tabel 5. Pengaruh kecepatan dan arah pencarian pada lingkungan 40 x 40

\begin{tabular}{|c|c|c|}
\hline \multirow{2}{*}{ Percobaan } & \multicolumn{2}{|c|}{$40 \times 40$} \\
\cline { 2 - 3 } & Speed 15, degree 0 & Speed 20, degree 10 \\
\hline 1 & 2956 & 1543 \\
\hline 2 & 4127 & 1758 \\
\hline 3 & 1712 & 2030 \\
\hline 4 & 1995 & 2116 \\
\hline 5 & 2763 & 2712 \\
\hline Rata-rata & 2710.6 ticks & 2031.8 ticks \\
\hline
\end{tabular}

Jika di representasikan dalam bentuk diagram garis maka hasilnya dapat dilihat pada Gambar 5.

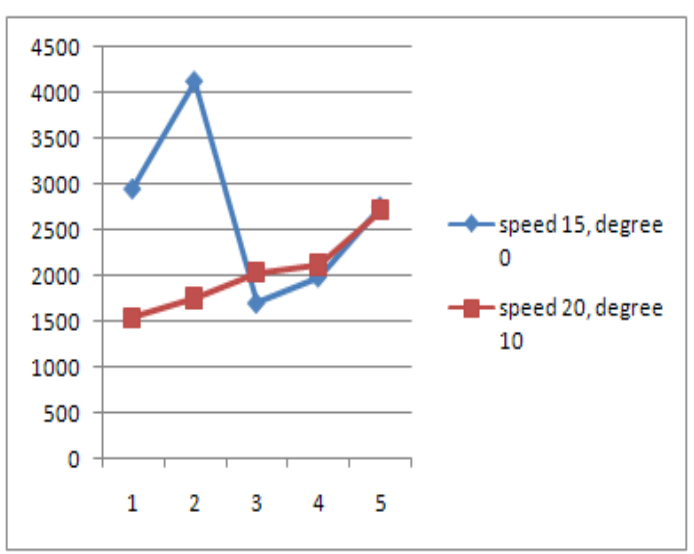

Gambar 5. Diagram garis hasil tabel 5 


\section{Pengujian II}

Berfokus menguji apakah dengan penambahan komunikasi dan derajat pencarian dapat menghilangkan stagnansi yang terjadi diakhir simulasi. Kesimpulan yang diperoleh dari pengujian II berdasarkan hasil pengujian Gambar 5, bahwa jumlah robot penanda dan pekerja yang lebih banyak berbanding lurus dengan kecepatan pembentukan cluster terutama pada lingkungan yang lebih kecil.

Inisialisasi objek pada lingkungan memiliki pengaruh pada kecepatan pembentukan cluster, semakin posisi objek tersebar secara merata semakin sulit bagi robot untuk mencarinya terutama pada lingkungan yang besar, derajat pencarian robot penanda dan pekerja yang lebih besar dapat membantu meningkatkan daya eksplorasi robot pada lingkungan sehingga dapat lebih cepat menjangkau posisi objek yang sulit ditemukan terutama yang berada pada sudut dan sisi lingkungan.

\section{Pengujian III}

Menggunakan input pengujian I dan II pada jenis lingkungan yang berbeda dan diperoleh hasil bahwa pada lingkungan yang lebih kecil (30 x 30) waktu stagnansi masih lebih singkat daripada lingkungan yang lebih besar (40x40) akan tetapi stagnansi masih tetap terjadi pada dua set parameter diatas, dari 20 kali pengujian yang dilakukan dengan set parameter yang berbeda. Tabel 6 memperlihatkan hasil plot yang ada tercipta pada pengujian I dan II yang akan dianalisis.

Tabel 6. Contoh pada ukuran lingkungan 40 x 40

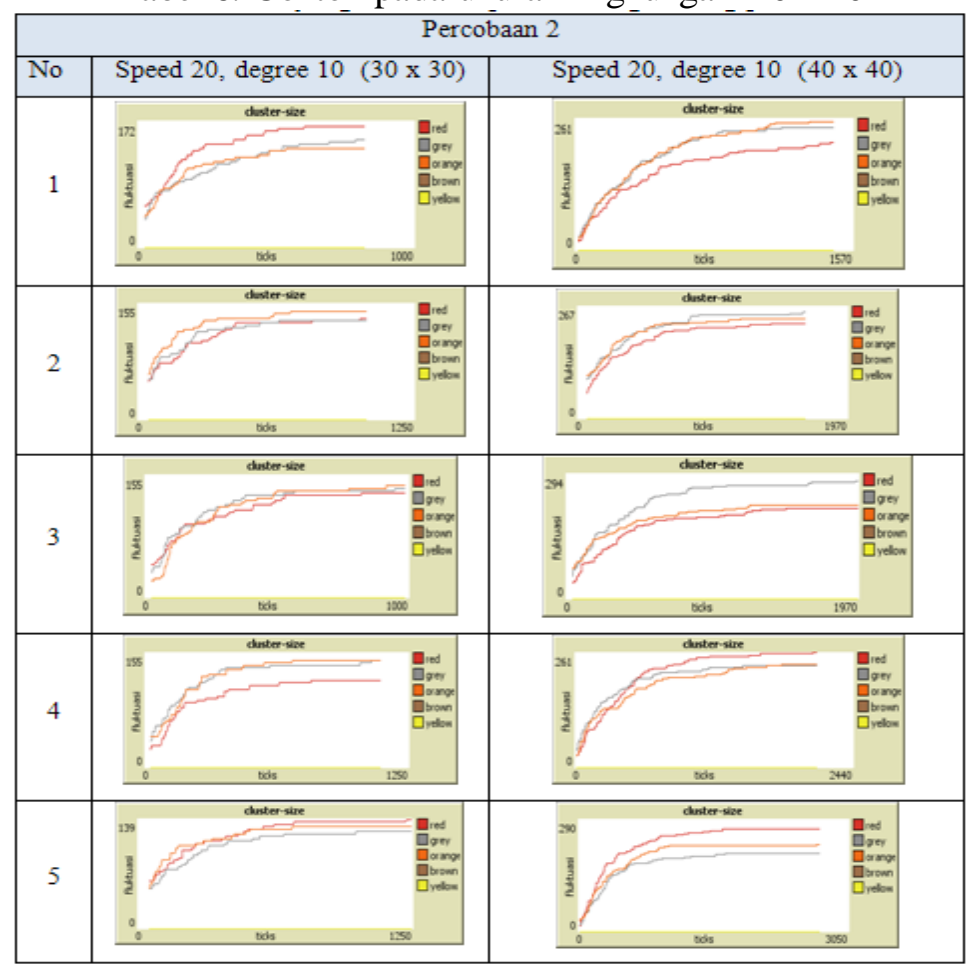

Berdasarkan pengujian pada Tabel 6, stagnansi diakibatkan antara lain :

1. penempatan objek pada saat inisialisasi proses diawal simulasi yang sulit ditemukan oleh robot rayap, baik penanda maupun pekerja [2].

2. Ukuran lingkungan yang digunakan.

3. Jumlah objek yang makin sedikit menjelang akhir simulasi

4. Jumlah robot yang sedikit. Jumlah robot mempersingkat stagnansi tetapi stagnansi masih terjadi .

IJCCS Vol. 6, No. 1, Jan 2012 : 33-42 
Dari tiga percobaan yang dilakukan terdapat beberapa hal penting yang dapat mempengaruhi kecepatan pencapaian solusi, antara lain :

- Pendekatan rayap merupakan pendekatan yang menitik-beratkan pada mekanisme randomness dalam mencapai solusi permasalahan. Sehingga walau dengan parameter yang sama dapat menghasilkan hasil yang berbeda pada setiap pengujiannya.

- Ukuran lingkungan mempengaruhi kecepatan proses clustering.

- Kecepatan dan derajat pencarian robot berguna pada saat menghadapi lingkungan yang besar dengan konsentrasi objek yang tersebar merata.

- Proses pembentukan cluster berjalan cepat diawal simulasi dan semakin lambat pada akhir simulasi yang berdampak pada munculnya stagnansi,dimana robot selalu bergerak tetapi kesulitan menemukan objek yang semakin sedikit pada lingkungan.

- Menurut [2] penempatan objek secara acak pada lingkungan mempengaruhi kecepatan pembentukan cluster

- Jumlah cluster dapat mempengaruhi alokasi robot rayap pekerja sedangkan speed dapat mempengaruhi kecepatan pencarian

- Jumlah marker yang besar mempercepat penandaan objek yang membuat rayap pekerja lebih efektif bekerja,sedangkan jumlah cluster menentukan alokasi rayap pekerja untuk menangani masing-masing cluster

\section{KESIMPULAN}

Kelebihan yang ada pada penelitian ini yaitu, perancangan model interaksi yang disimulasikan menggunakan salah satu metodologi perancangan berbasis agent IODA yang berdasarkan tinjauan pustaka belum pernah diimplementasikan pada Netlogo, kemudian simulasi tidak hanya berfokus pada pengembangan behaviour robot saja seperti pada beberapa peneltian sebelumnya tetapi telah melihat konsep pendekatan rayap secara keseluruhan dengan penggunaan mekanisme komunikasi tidak langsung dan modelling interaksi yang terjadi diantara robot.

Diluar dari hasil penelitian, simulasi ini dapat memperlihatkan pergerakan salah satu robot yang ingin diteliti, dari sepengetahuan penulis, fitur tersebut belum digunakan pada penelitian-penelitian sebelumnya yang diacu pada penelitian ini.

Kekurangan yang pada penelitian ini berdasarkan hasil pengujian antara lain mekanisme simulasi yang dilakukan belum dapat menghilangkan stagnansi yang terjadi pada simulasi, akan tetapi berdasarkan pengujian yang dilakukan dengan penambahan derajat pencarian dan penyesuaian terhadap faktor jumlah robot serta ukuran lingkungan dapat mempersingkat waktu stagnansi dari sebelumnya.

Sedangkan jika dilihat dari sudut pandang sistem, posisi dari cluster belum dapat ditetapkan pada suatu tempat, penempatan cluster masih bersifat acak pada lingkungan, bagaimana jika posisi cluster dapat ditentukan penempatannya berdasarkan petunjuk tertentu seperti intensitas feromon dan lain sebagainya.

\section{SARAN}

Berdasarkan kekurangan yang diperoleh dari hasil pengujian, masih terjadi stagnansi pada sistem yang dibuat, untuk mengatasi hal tersebut penyesuaian terhadap beberapa faktor yang menyebabkan stagnansi harus dilakukan antara lain dengan penggunaan jumlah robot yang sebanding dengan objek yang akan di cluster dan mempertimbangkan pula ukuran lingkungan yang digunakan. Jumlah robot yang banyak tetapi tidak efektif dalam pergerakan pencariannya tidak berpengaruh banyak terhadap penanganan stagnansi.

Penelitian selanjutnya diharapkan dapat mengatasi stagnansi yang masih terjadi selama proses simulasi, dengan cara meningkatkan kemampuan pencarian robot karena stagnansi dapat 
memboroskan sumber daya robot jika nantinya diimplementasikan dalam bentuk robot fisik dan penempatan cluster dapat ditentukan pada koordinat tertentu pada lingkungan berdasarkan stimulus yang ditinggalkan oleh koloni robot itu sendiri.

\section{DAFTAR PUSTAKA}

[1] Sahin. E, Girgin. S, Bayindir.L, Turgut. A, 2005, Swarm Robotics. Team SequeL, INRIA Futurs Lille, 59650, Villeneuve d'Ascq, Turkey.

[2] Wang.T dan Zhang.H, 2008, Multi-Robot Collective Sorting with Local Sensing, Journal, University of Alberta, Canada.

[3] Ozturk.S, Esin.E, 2003, Simulation of swarm Intelligent And Possible Application in Engineering, Mathematical and Computational Application, Vol 8, no 3, pp 361-368

[4] Ghnemat. R, 2006, Collective Intelligence based on Multi-Agent and Ant Systems for Swarm Robotic, Thesis, Al-Balqa' Applied University. Salt, Jordan.

[5] Bonabeau. E, Dorigo. M, Theraulaz. G, 1999, Swarm Intelligent, Oxford University Press, New York.

[6] Beckers. R., Holland. O, dan Deneubourg. J, 1994, From local actions to global tasks:Stigmergy and collective robotics. Artificial Life IV: Proceedings of the fourth international workshop on the synthesis and simulation of living systems, Cambridge, MA. MIT Press.

[7] Kubera. Y, Mathieu. P, Picault. S, 15 January 2011, IODA: an interaction-oriented approach for multi-agent based simulations, Auton Agent Multi-Agent Syst, Springer. 